\title{
O UNIVERSO DA DISCUTÍVEL UNIVERSALIDADE DO SISTEMA ÚNICO DE SAÚDE
}

\author{
THE UNIVERSE OF DISCERNIBLE UNIVERSALITY
}

OF THE SINGLE HEALTH SYSTEM

Recebido em 29/11/2017

Aprovado em 20/02/2018

\author{
MARCO ANTONIO BARBOSA DE FREITAS1 \\ AMELIA COHN ${ }^{2}$ \\ ROSA MARIA FERREIRO PINTO ${ }^{3}$
}

RESUMO: O artigo aborda a discutível universalidade do Sistema Único de Saúde. Por proêmio, discorre acerca do alcance e da compreensão do Direito à Saúde, previsto na Constituição Federal, estruturado por meio do Sistema Único de Saúde. A seguir, destaca a importância do orçamento público nos gastos com a saúde, especialmente a necessidade ao respeito às receitas, à estimativa de despesas e à correspondente destinação dos recursos. Em seguida, aborda o sistema misto adotado no Brasil, bem como a participação das empresas privadas na prestação de serviços na área da Saúde para a compreensão da ideia de universalidade desse direito. Assim, analisa o sentido da integralidade previsto na norma constitucional, cujo destinatário é a pessoa e não o serviço. Por fim, estabelece a dicotomia entre a teoria da reserva do possível e do mínimo existencial, apontando o reconhecimento da mencionada teoria pelo Supremo Tribunal Federal em sede de repercussão geral, concluindo-se que não basta a pretensão, mas a razoabilidade do que se almeja do Estado na área da Saúde.

PALAVRAS-CHAVE: Saúde, Universalidade, Destinatário, Judicialização.

\begin{abstract}
The article discusses the questionable universality of the Unified Health System. First, it discusses the scope and understanding of the Right to Health, foreseen in the Federal Constitution, structured through the Unified Health System. Next, it highlights the importance of the public budget in health expenditures, especially the need to respect revenues, estimate expenditures and the corresponding allocation of resources. It then discusses the mixed system adopted in Brazil, as well as the participation of private companies in the provision of health services to understand the idea of universality of this right. Thus, it analyzes the sense of wholeness provided in the constitutional norm, whose recipient is the person and not the service. Finally, it establishes the dichotomy between the theory of the reserve of the possible and the existential minimum, pointing out the recognition of the aforementioned theory by the Federal Supreme Court in a general repercussion, concluding that it is not enough the pretension, but the reasonableness of what is sought of the State in the area of Health.
\end{abstract}

KEYWORDS: Health, Universality, Addressee, Judicial.

\footnotetext{
1 Juiz de Direito do Tribunal de Justiça do Estado de São Paulo; Professor titular de Direito Processual Civil na Faculdade de Direito da Universidade Santa Cecília/SP; Mestre em Direito da Saúde pela Universidade Santa Cecília/SP.

2 Doutora em Sociologia pela Universidade de São Paulo; membro da ASSOCIAÇÃO BRASILEIRA DE SAÚDE COLETIVA; Professora do programa de Mestrado em Direito da Saúde: dimensões individuais e coletivas, Universidade Santa Cecília.

${ }^{3}$ Doutora em Serviço Social pela Pontifícia Universidade Católica de São Paulo; fundou e coordenou o NEPEC Núcleo de Estudos e Pesquisas em Condições Sociais e Saúde Coletiva de 2003 a 2013; Professora do Mestrado em Direito da Saúde: dimensões individuais e coletivas da Universidade Santa Cecília.
} 


\section{INTRODUÇÃO}

Criado pela Constituição Federal de 1988, o Sistema Único de Saúde - SUS - é um dos maiores sistemas públicos de saúde no mundo ${ }^{4}$, abrangendo desde o atendimento ambulatorial até procedimentos mais complexos, como, por exemplo, o transplante de órgãos.

Diferentemente, antes de 1988, o SUS atendia tão somente aqueles que contribuíam com a Previdência Social, restando à população carente valer-se de filantropia (ou caridade) para obter os serviços básicos de saúde.

Com efeito, a Constituição traz um conceito amplo do acesso à saúde, garantindo que esse direito social seja universal, gratuito, integral e igualitário a toda população do país, desde a gestação.

Adota-se a concepção de que a saúde não consiste apenas no ato de não adoecer ou em coibir a propagação de doenças que atinjam a coletividade, mas na responsabilidade de o Poder Público promover, prevenir e recuperar a saúde, com a formulação e execução de políticas sociais, em uma visão epistemológica do tema.

O texto constitucional confere ao Estado, assim, o dever de organizar as ações e serviços públicos de saúde a partir da outorga de instrumentos administrativos, institucionais e financeiros necessários para garantir o direito à saúde aos mais de 200 milhões de brasileiros.

De fato, “a Constituição Federal de 1988 diz que a saúde é direito de todos e dever do Estado. Isso deve ser garantido por políticas públicas sociais e econômicas, reduzindo o risco de doença e promovendo acesso universal e igualitário às ações e serviços para promoção, proteção e recuperação da saúde. A saúde deve ser compreendida como qualidade de vida e não apenas como ausência de doenças" 5 .

Resta evidente que a mens legis tratou o SUS como uma política pública de Estado que amplia os direitos sociais e concretiza o acesso à saúde, enumerando, para tanto, princípios e diretrizes norteadores do Poder Público, como o atendimento integral, estampado no artigo 198, inciso II, da Carta Magna.

\footnotetext{
4 Disponível em: <http://portalsaude.saude.gov.br/index.php/cidadao/entenda-o-sus >

5 Disponível em: <http://www.ccms.saude.gov.br/sus20anos/mostra2009/aconstituicao.html>
} 
Contudo, há de se perquirir se a universalidade prevista na Constituição significa que todo e qualquer procedimento de saúde, independente da complexidade e do seu custo, deve ser disponibilizado pelo Sistema Único de Saúde, de forma integral.

Nessa toada, propõe-se a análise do alcance conceitual da universalidade lá preconizada e da concepção do princípio da integralidade em cotejo com os demais princípios, normas e valores espraiados no texto constitucional.

\section{A PREVISÃo dA SAÚde COMO DIREITO SOCIAL NA CONSTITUIÇÃo} FEDERAL DE 1.988

O enfoque deste artigo - reconheça-se desde o início dele - não é o que se poderia denominar de tarefa fácil, na medida em que aqui o que se tenciona é propor reflexão que não destoe do razoável e do indispensável bom senso, quando se debruça por sobre a amplitude do Direito à Saúde no âmbito público, mais especialmente no que concerne o alcance do que buscou o legislador constituinte ao redigir o cediço artigo 196, da Constituição Federal ${ }^{6}$.

Isto porque tal dispositivo magno não parece ceder espaço - sobretudo aos puristas, que costumam conceber nossa Constituição Federal como expressão pronta, acabada e inteiramente autossuficiente no seu espectro de vigência e correlata aplicação -, à interpretação que suscite algum abrandamento à ideia que brada ser a saúde "direito de todos e dever do Estado (...)”, garantindo “acesso universal igualitário às ações e serviços para sua promoção, proteção e recuperação." (grifos nossos)

A previsão é bela e as razões são nobres, corolário indubitável do princípio da dignidade humana, disso não se pode cogitar a mais tênue dúvida; contudo, de outro tanto, também não se pode perder de vista que, partindo-se do dito popular de que a teoria é outra, quando posta em prática - mormente quando há pronunciadas circunstâncias sócioeconômicas típicas de um país capitalista semiperiférico -, é preciso não olvidar que, como sói, a realidade se impõe.

Nessa esteira, entende a doutrina que:

\footnotetext{
${ }^{6}$ Art. 196. A saúde é direito de todos e dever do Estado, garantido mediante políticas sociais e econômicas que visem à redução do risco de doença e de outros agravos e ao acesso universal e igualitário às ações e serviços para sua promoção, proteção e recuperação.
} 


\begin{abstract}
Mesmo que o sistema de saúde tenha a atuação preventiva e curativa absolutamente iguais, as pessoas que vivem em situação precária fatalmente serão mais acometidas de doenças e outros agravos, ainda que o sistema de saúde lhe ofereça um excelente serviço de recuperação de seus agravos.

Daí se pode afirmar que, sem a redução das desigualdades sociais, a erradicação da pobreza e a melhoria do modo de vida, o setor da saúde será o estuário de todas as mazelas das más políticas sociais e econômicas?
\end{abstract}

No entanto, ainda nesse giro verbal, é curial anotar que, mesmo fosse o Brasil nação que integrasse o seleto escalão dos países plenamente desenvolvidos, não seria possível dar absolutamente tudo a absolutamente todos, até porque, em muitas dessas nações, o sistema de saúde não ousou ir tão longe, presumivelmente vinculado a um mundo em que se espera que demandas nessa área tenham alguma ligação com o seu correspondente orçamento - do que infelizmente pouco se discute no Brasil.

Este é, portanto, o desafio central deste trabalho: buscar o alcance e a compreensão de que a Saúde, como Direito Social fundamental versado em nossa Lex Major nos artigos $6^{\circ}$ e 196 a 200, estruturado por meio de um autodenominado Sistema Único de Saúde (SUS), gerido e financiado em coparticipação por União, Estados, Distrito Federal e Municípios - e que é regulado pela Lei ${ }^{\circ} 8.080 / 90$-, enfrenta concretamente limites de toda sorte.

Nesse diapasão, o que se quer aqui é, assim, desenvolver raciocínio que pondere sobre o universo desse direito essencial, que para alcançar a todos indistintamente - um de seus misteres -, não pode e não deve, ao que se nos afigura, ser visto como fonte inesgotável de cobertura de serviços e medicamentos, cujo custeio encontra limites que precisam ser administrados com cuidadoso senso de responsabilidade, levando em conta a primazia do interesse público

\title{
3 GASTOS PÚBLICOS NA SAÚDE E A CONTRAPARTIDA ORÇAMENTÁRIA
}

A Constituição Federal de 1988, no artigo 165, institucionalizou as regras orçamentárias no país com a definição de três normas jurídicas: Plano Plurianual (PPA)

7 SANTOS, Lenir. Direito à Saúde, Sistema Único de Saúde e a Integralidade da Assistência. In: Direito da Saúde no Brasil. André Evangelista de Souza et al. Organizadora: Lenir Santos. São Paulo, Saberes Editora, 2010, p. 149. 
definidor do conjunto de políticas públicas do governo para o período de quatro anos; Lei das Diretrizes Orçamentárias (LDO), elaborada anualmente para apontar as prioridades da administração pública e Lei Orçamentária Anual (LOA), que especifica o orçamento anual propriamente dito, define todos os gastos do governo para o ano subsequente e abarca em seu conteúdo a estimativa de receita e a previsão das despesas públicas.

Acerca do tema, esclarece a doutrina que:

\begin{abstract}
A Constituição Federal de 1988 institucionalizou um verdadeiro sistema orçamentário ao prever a edição de uma lei de plano plurianual, lei de diretrizes orçamentárias, e lei do orçamento anual, todos atos normativos que, de forma hierarquizada, se interligam com o objetivo de dotar o setor público de um processo de planejamento orçamentário que espelhe um plano de governo a longo, médio e curto prazos (arts. 165 e 166) .
\end{abstract}

Anteriormente, a Emenda Constitucional n ${ }^{0} 29$ determinava que os gastos da União deveriam ser iguais ao do ano anterior, corrigidos pela variação nominal do Produto Interno Bruto (PIB). Os Estados, por sua vez, deveriam garantir $12 \%$ de suas receitas para o financiamento à saúde e os municípios precisam aplicar pelo menos $15 \%$ de suas receitas. ${ }^{9}$

Contudo, em 15 de dezembro de 2016, o Congresso Nacional promulgou a PEC 55, que limita os gastos públicos em 20 anos, objetivando equilibrar as contas públicas, por meio de um rigoroso controle de gastos.

De acordo com a Emenda Constitucional 95, o teto para 2017 foi definido com base na despesa primária paga em 2016, com a correção de 7,2\%, a inflação prevista para o ano; a partir de 2018, os gastos federais só poderão aumentar de acordo com a inflação acumulada conforme o Índice Nacional de Preços ao Consumidor Amplo (IPCA). O regime vale para os orçamentos fiscal e da seguridade social e para todos os órgãos e Poderes da República. 10

O orçamento público brasileiro tornou-se uma responsabilidade dos três poderes, já que realizado em quatro fases distintas: elaboração da proposta no âmbito do Poder Executivo; apreciação e votação pelo Poder Legislativo; execução pelos poderes executivos, por fim, o controle dessa sua implementação pelos órgãos do judiciário.

\footnotetext{
${ }^{8}$ MEIRELLES, Hely Lopes. Direito Municipal Brasileiro. 14ª Ed. São Paulo: Malheiros, 2006, p.266.

${ }_{9}$ Disponível em: < http://portalarquivos.saude.gov.br/images/pdf/2013/agosto/28/cartilha-entendendo-osus-2007.pdf>

10 Disponível em <https://www12.senado.leg.br/noticias/materias/2016/12/15/promulgada-emendaconstitucional-do-teto-de-gastos $>$
} 
Nele estão contidas as receitas arrecadadas e a estimativa de gastos que o governo terá em um exercício, ou seja, tudo que almeja receber o Poder Público e a correspondente destinação desses recursos.

Sua elaboração, por isso, envolve uma série de estudos bem como o planejamento de todas as ações que serão realizadas pelo governo no próximo exercício fiscal. Assim, com base na receita prevista, os Poderes Executivo, Legislativo e Judiciário fixam suas despesas, confeccionando a respectiva proposta orçamentária, que aprovada, passa a ser executada.

É notória a complexidade do processo orçamentário e sua vasta abrangência em conter as receitas arrecadadas e a estimativa de gastos do governo em um exercício, ou seja, tudo que almeja receber o poder público e a correspondente destinação desses recursos; destarte, sua elaboração envolve uma série de estudos, assim como o planejamento de todas as ações que serão realizadas pelo governo no próximo ano.

Tudo que for gasto pelo poder público, tanto as despesas correntes como os investimentos devem estar previstos em lei orçamentária para que as contas públicas alcancem sua legitimidade.

Conforme nos ensina Áquilas Mendes ${ }^{11}$ :

"O gasto em saúde deve estar ligado ao planejamento, como um instrumento que baliza o orçamento. Se o gasto é caracterizado por um dispêndio de recursos, representado por uma saída de recursos financeiros, esse só pode ser viabilizado se estiver em acordo com o que foi planejado e orçado. É importante assinalar que nenhum gasto deverá ser realizado sem que haja disponibilidade de recursos orçamentários e financeiros. Para tanto é importante que se resgate o planejamento como primeira função da gestão orçamentário-financeira."

No contexto da saúde pública brasileira, em que a universalidade é interpretada como um direito ilimitado, obtido, muitas vezes, em decisões judiciais proferidas costumeiramente sem a observância da contrapartida orçamentária, o planejamento público apresenta-se seriamente comprometido, e o sonho da prestação universal da saúde, em sua decorrência, torna-se ainda mais distante.

Destaca-se que o governo federal é o preponderante financiador da rede pública de saúde. Reconhecidamente, o Ministério da Saúde aplica metade de todos os recursos gastos no

\footnotetext{
11 MENDES, Áquilas. A busca da cumplicidade entre o planejamento e o processo orçamentário na saúde paulistana. In: MENDES Áquilas; SOUZA, Maria de Fátima de (Orgs). Tempos radicais da saúde em São Paulo: a construção do SUS na maior cidade brasileira. São Paulo: Hucitec, 2003.p.116-117.
} 
país em saúde pública em todo o Brasil, enquanto Estados e municípios, em regra, concorrem com a outra metade dos subsídios. 12

Veja-se que o Projeto de Lei Orçamentária Anual 2017 (PLOA) que foi entregue ao Congresso Nacional, no caso da saúde, prevê despesas de R \$ 110,2 bilhões - valor 7,20\% maior que o de 2016 e 6,06\% que o valor mínimo que o governo é obrigado por lei a desembolsar (Fonte Portal do Planalto13).

É certo que a saúde como direito fundamental é universal em sua essência, mas entendemos que a universalidade necessita ser vista como a disponibilização a todos da estrutura de saúde existente e não a viabilização a qualquer um de qualquer serviço, procedimento ou equipamento, o que destoa do razoável e caminha na contramão de um planejamento orçamentário economicamente viável.

De fato, "o SUS mantém-se econômica e financeiramente estritamente com recursos públicos, oriundos do orçamento da seguridade social, bem como dos orçamentos fiscal federal, estaduais, distrital e municipais"14.

Destarte, neste contexto o Poder Judiciário não pode se imiscuir de apreciar as demandas que lhe são trazidas com esteio em alegada ofensa ao artigo 196, da Constituição Federal; contudo, não deve carrear para si o papel de realizador das políticas públicas, assegurando infindáveis direitos aos que lhe acorrem, comprometendo o mínimo inescusável aos que dele não se socorrem.

Nessa vereda, confira-se o crescente número de ações judiciais no país como um todo para o acesso ao Sistema Único de Saúde:

12 Disponível em: < http://portalarquivos.saude.gov.br/images/pdf/2013/agosto/28/cartilha-entendendo-osus-2007.pdf>

13 Disponível em: <http://www2.planalto.gov.br/acompanhe-planalto/noticias/2016/09/governo-elevaorcamento-de-2017-para-saude-e-educacao>

14 WEICHERT, Marlon Alberto. Direito à saúde, Sistema Único de Saúde e a integralidade da assistência. In: Direito da Saúde no Brasil. André Evangelista de Souza et al. Organizadora: Lenir Santos. São Paulo, Saberes Editora, 2010, p. 105. 


\section{SAÚDE NA JUSTIÇA}

Cresce o volume de ações contra o governo por medicamentos e tratamento

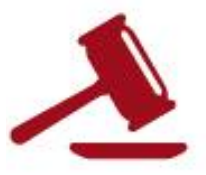

\section{CUSTO TOTAL*}

Total repassado para cumpri-

mento de açōes judiciais,

por ano, em R\$ milhōes (corrigidos pela inflaçāo**)

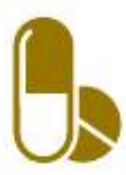

CUSTO PARA REMÉDIOS*

Apenas para fornecer medi-

camentos após açōes contra a

Uniāo, por ano, em R\$ milhōes

(corrigidos pela inflaçāo**)

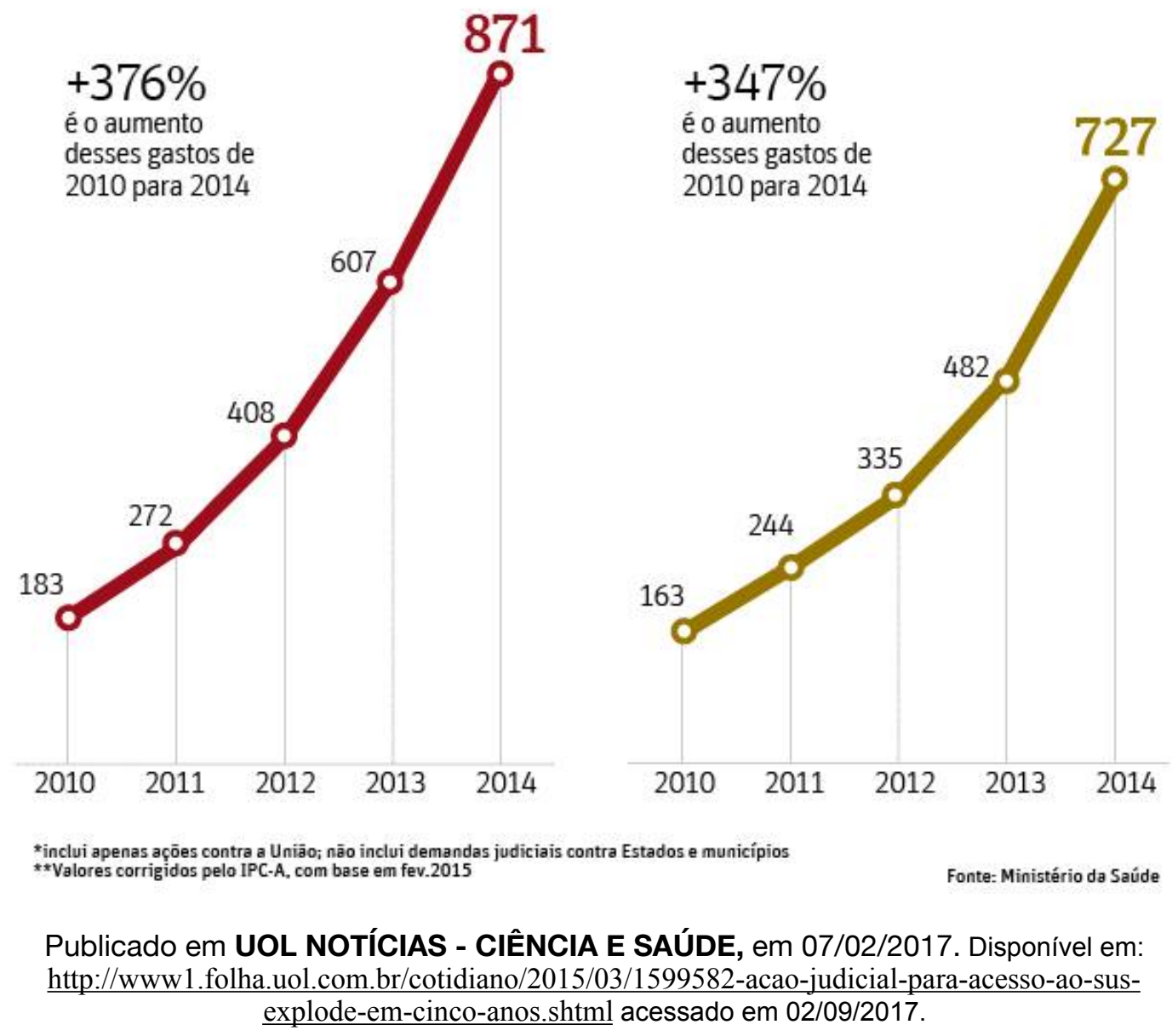

Já em pesquisa coordenada pelo Professor Mário Scheffer, da FMUSP (Faculdade de Medicina), apurou-se que, em 2011, o total de ações na primeira instância, no Estado de São Paulo, somava 2.602. Em 2016, houve um aumento de $631 \%$, saltando para 19.025 , sendo que em seis anos o número de ações judiciais em primeira instância chegou a 77 mil ${ }^{15}$.

Diante desse cenário, esclarece Scheffer ${ }^{16}$ que:

15 Disponível em: $<$ https://noticias.uol.com.br/saude/ultimas-noticias/redacao/2017/02/07/acoes-na-justica-de-spcontra-planos-de-saude-aumentam-631-desde-2011.htm> Acesso em 02/09/17.

16 SCHEFFER, Mário. Coberturas Assistenciais negadas pelos Planos e Seguros de Saúde em ações julgadas pelo Tribunal de Justiça do Estado de São Paulo. Revista de Direito Sanitário, São Paulo, v. 14, n. 1, p. 122-132, mar./jun. 2013. 


\begin{abstract}
“A restrição de coberturas na assistência médica suplementar, tema recorrente nos tribunais, repercute na saúde e na vida da população usuária, bem como nos custos administrativos das empresas de planos e seguros de saúde, mas também interfere no sistema público de saúde, pois os limites de atendimento inscritos nos contratos de planos de saúde, previstos na legislação ou autorizados pela Agência Nacional de Saúde Suplementar (ANS), são absorvidos, em grande parte, pelo SUS”.
\end{abstract}

Na mesma vertente, Lígia Bahia ${ }^{17}$ arremata:

“A judicialização da saúde veio para ficar. Poderá consolidar-se apenas como um
estuário para as insatisfações, aprimorando os critérios técnicos de suas decisões, ou
estender sua força para a abertura de um processo de compreensão e
operacionalização da saúde como um direito expansivo. A indeterminação do direito
à saúde requer a criação de uma arena pública na qual os poderes Executivo e
Legislativo sejam interpelados por entidades da sociedade civil que procuram
completar o sentido de proposições ainda incipientes, como as voltadas ao
desenvolvimento industrial e científico do setor, e explicitar e se opor a normas
legais contrárias ao SUS. Cabe aos órgãos públicos indicar de modo transparente e
compreensível as reais possibilidades de atendimento de necessidades básicas de
saúde”.

Depreende-se que o Poder Executivo, em todas as suas esferas de governo, tem, inegavelmente, comprometido seu orçamento - inviabilizando, por consequência, diversos projetos na área da saúde - frente ao excessivo número de processos, sendo certo que a tutela jurisdicional deveria ser concedida somente em caráter excepcional, em caso de flagrante ilegalidade, o que - em muitas hipóteses - não se verifica.

Traçando um paralelo com o sistema de saúde alemão ${ }^{18}$, o mais antigo do mundo com caráter universal - em que $11 \%$ do PIB são investidos em saúde, com custo de 15,5\% da renda do assalariado, atendendo também aos familiares próximos (cônjuge e filhos) -, e o brasileiro - em que os gastos públicos com saúde representam apenas 3,6\% do PIB (dados de 2008) e atende a todos que dela necessitam independentemente de estarem contribuindo para o sistema de seguridade social -, percebe-se a gritante diferença entre a fonte de recursos amealhados e investidos, além do alcance do atendimento.

Todavia, mesmo o sistema alemão, com uma gama ampliada de investimentos é considerado ineficiente, com várias reclamações pautadas principalmente na falta de profissionais para atendimento médico. Assim, pouco restará ao sistema brasileiro, que conta com uma amplitude infinitamente menor de recursos e uma exigência cada vez maior de cobertura.

17 Disponível em <https://oglobo.globo.com/opiniao/a-judicializacao-da-saude-11334080> Acesso em 02/09/2017.

18 AGUIAR, Flávio. Eficiente e Deficiente: o sistema de Saúde na Alemanha. Disponível em < http:// www.cartamaior.com.br/?/Coluna/Eficiente-e-deficiente-o-sistema-de-saude-na-Alemanha/20685> Acesso em: $10 / 07 / 2017$ 
Com efeito, a escassez de recursos públicos no Brasil deve ser considerada, pois seria ingênuo acreditar que o Estado pode fornecer a todos qualquer prestação na área da saúde, o que não ocorre nem mesmo nos países em condição econômica privilegiada.

O direito à saúde deve ser considerado, sim, por meio de políticas públicas, observada sempre a racionalização e a garantia da igualdade de acesso a todos, em sua mais completa essência.

\section{O SISTEMA MISTO ADOTADO NO BRASIL E A PARTICIPAÇÃO DAS EMPRESAS PRIVADAS NA PRESTAÇÃO DE SERVIÇOS NA ÁREA DA SAÚdE}

O legislador constituinte, consciente de que o Estado, como se fora um Leviatã, jamais teria meios de, isoladamente, prestar tal indispensável serviço de forma eficiente e sustentável - em especial do ponto de vista econômico -, previu expressamente no artigo 197, da Constituição Federal, que, paralelamente, se incumbiria da "regulamentação, fiscalização e controle (...)” da prestação de serviços nessa área, que, destarte, poderiam ser executados “através de terceiros e, também, por pessoa física ou jurídica de direito privado".

A Lei Federal 13.097/15, por sua vez, passou a permitir a participação direta ou indireta, inclusive controle, de empresas ou de capital estrangeiro na assistência à saúde nos casos de pessoas jurídicas destinadas a instalar, operacionalizar ou explorar hospital geral (inclusive filantrópico), hospital especializado, policlínica, clínica geral e clínica especializada, ações e pesquisas de planejamento familiar, evidenciando que as atividades de apoio à assistência à saúde são livres ao capital estrangeiro.

O artigo 199 da Carta Magna reforça essa atuação concedida à iniciativa privada, como meio de complementar o Sistema Único de Saúde, "segundo diretrizes deste”.

Essa previsão e a sua consequente execução - tal como se assistiu cerca de quatro décadas antes, no Sistema Educacional, outro dos Direitos Sociais constantemente em xeque erigiu o que se convencionou nominar de sistema misto, que nas palavras de André da Silva Ordacgy ${ }^{19}$, tem sido desvirtuado, principalmente, por má gestão:

19 ORDACGY, André da Silva. O direito humano fundamental à saúde pública. Disponível em: $<$ W artigo_20080925170800ARTIGO_SAUDE_PUBLICA_ANDRE_ORDACGY_ESDPU.pdf.> Acesso em: 31.08. $\overline{2} 009$. 
"O Brasil adota um sistema misto de saúde (público e privado), visto que a assistência à saúde é livremente assegurada à iniciativa privada, de forma complementar, por força do art. 199 da CF. Infelizmente, a má gestão administrativa e financeira do SUS, o sucateamento dos grandes hospitais públicos, a escassez de profissionais médicos e o desvio de verbas da saúde têm prejudicado demasiadamente o sistema público de saúde, a ponto de sua inoperância servir como veículo de propaganda em favor dos planos privados de saúde".

A possibilidade de que pessoas jurídicas de direito privado de capital nacional ou internacional realizem tais serviços, debaixo de controle, de fiscalização e até de severa regulação do Estado - por intermédio da Agência Nacional de Saúde Suplementar (ANS), criada pela Lei $\mathrm{n}^{\mathrm{o}} 9.961 / 00$-, que assim predetermina quais devem, obrigatoriamente, ser prestados aos que a elas se vinculam juridicamente, tem causado não pouco estranhamento, por gerar indisfarçável inversão do conceito cultivado constitucionalmente.

Em outro giro verbal, significa dizer que o Estado, desde a promulgação da Carta de 1988, ao se dar conta de que não bem conseguiria se desvencilhar desse poder-dever, garantindo diretamente o direito à saúde a todos, aliado principalmente aos interesses do setor privado, paulatinamente passou, de forma sutil, a transferir à iniciativa privada essa responsabilidade, paradoxalmente exigindo dela a amplitude de serviços que, não raro, nem mesmo ele tem prestado.

Em uma interpretação particular acerca desse insidioso iter, a doutrina abalizada observa que:

\begin{abstract}
"Por outro lado, se a Constituição admite que a entidade privada participe complementarmente do SUS, isso, à evidência, não autoriza o Poder Público a instituir uma série de exigências para melhorar o atendimento à saúde como se estivesse fazendo alguma coisa em prol da melhoria no atendimento aos pacientes - sem ofertar contrapartida adequada, transferindo ao particular todos os custos e ônus dessas ações. (...) Aliás, é de se perquirir com que autoridade o Estado irá desempenhar o maior poder de controle sobre o particular - quando este a exerce as atividades consideradas de relevância pública sob regime de direito privado, nos moldes do que estabelece o art. 197 da CF -, se atua de forma irresponsável, deixando de fazer sua parte, quando a assistência se dá sob regime de direito público."20
\end{abstract}

Tais considerações merecem ser feitas, visto que essa distorção tem ensejado a incontida judicialização do Direito à Saúde, tanto no âmbito público - particulares buscando

20 MARTINS, Ives Gandra da Silva; SOUZA, Fátima Fernandes Rodrigues de. Serviços de saúde. Relevância pública independente do regime de sua prestação. Participação da iniciativa privada em caráter complementar ao SUS. Direito à manutenção do equilíbrio econômico e financeiro dos contratos e/ou convênios celebrados com a administração. Reajuste e recomposição de preços. Exigência constitucional e da legislação ordinária para que os valores repassados reflitam os impactos da inflação e do aperfeiçoamento tecnológico dos procedimentos. Parecer. Revista IOB de Direito Administrativo, vol. 2, n. 14, São Paulo, IOB Thomson, fev. 2007, p. 116 
em ações contra União, Estados, Distrito Federal e Municípios a aplicação plena do supracitado artigo 196 -, quanto no âmbito privado - contratantes de planos ou seguros de saúde tencionando cobertura suplementar e integral, ante a inaptidão do Estado em dar cabo da tal universalidade lá cogitada.

Não foi outro o olhar do Ministro Luiz Roberto Barroso ${ }^{21}$, em artigo a esse respeito:

"Ocorre que, em uma ordem jurídica pluralista, a Constituição abriga
princípios que apontam em direções diversas, gerando tensões e eventuais
colisões entre eles. Estes entrechoques podem ser de três tipos: a) colisão
entre princípios constitucionais, como, e.g., a livre iniciativa versus a
proteção do consumidor, na hipótese de se pretender tabelar o preço de
determinado medicamento; b) colisão entre direitos fundamentais, como,
e.g., o direito à vida e à saúde de uma pessoa versus o direito à vida e à
saúde de outra pessoa, na hipótese de ambas necessitarem com urgência de
transplante de determinado órgão, quando só exista um disponível; c)
colisão entre direitos fundamentais e outros princípios constitucionais,
como, e.g., o direito à saúde versus a separação de Poderes, no caso de
determinadas opções legais ou administrativas acerca de tratamentos a
serem oferecidos". acerca do tema e da má compreensão estatal - intencional ou não, pouco importa a esta altura -, principalmente no tocante à amplitude, objetiva e subjetiva, de sua fulcral atribuição em garantir acesso ao Direito à Saúde aos seus, que emerge a necessidade de algumas ponderações que desbordam para a necessidade de mais precisa definição do que se pode extrair da ideia da universalidade de sua fruição.

\section{A COMPREENSÃO DA IDEIA E DO DESTINATÁRIO DA UNIVERSALIDADE DO DIREITO À SAÚDE}

Consoante se disse alhures, o direito fundamental à saúde está, assim como outros, consagrado na Constituição Federal de forma genérica, no artigo $6^{\circ}$ e, de maneira pormenorizada, nos seus artigos 196 e 198.

Vislumbra-se no aludido artigo 196 da Carta Magna que cabe ao Estado a promoção da saúde, instituindo políticas sociais com o fito de reduzir o risco de doenças, bem como garantir o "acesso universal e igualitário às ações e serviços para sua promoção, proteção e recuperação".

21 BARROSO, Luiz Roberto. Da falta de efetividade à judicialização excessiva: direito à saúde, fornecimento gratuito de medicamentos e parâmetros para a atuação judicial. Disponível em: <www.lrbarroso.com.br/pt/ noticias/medicamentos.pdf. $>$ Acesso em: 12.09.2009. p. 8 
Segundo os doutrinadores Luiz Alberto David Araújo e Vidal Serrano Nunes Jr. ${ }^{22}$, o art. 196 da Constituição Federal veicula dois princípios constitucionais relacionados à saúde, o do acesso universal e o do acesso igualitário:

"O princípio do acesso universal traduz que os recursos e ações na área de saúde pública devem ser destinados ao ser humano enquanto gênero, não podendo, portanto, ficar restritos a um grupo, categoria ou classe de pessoas. (...)

"O princípio em pauta é complementado logicamente pelo princípio do acesso igualitário, cujo significado pode ser traduzido pela máxima de que pessoas na mesma situação clínica devem receber igual atendimento, inclusive no que se refere aos recursos utilizados, prazos para internação, para realização de exames, consultas etc."

Noutra quadra, o artigo 198, de nossa Carta Máxima, arrola as diretrizes que devem ser observadas nas ações e serviços públicos de saúde que integram o Sistema Único de Saúde. Confira-se:

Art. 198. As ações e serviços públicos de saúde integram uma rede regionalizada e hierarquizada e constituem um sistema único, organizado de acordo com as seguintes diretrizes:

I - descentralização, com direção única em cada esfera de governo;

II - atendimento integral, com prioridade para as atividades preventivas, sem prejuízo dos serviços assistenciais;

III - participação da comunidade.

Primu ictu oli, a singela leitura dos citados dispositivos legais pode criar a sensação de que é dever do Poder Público prestar integralmente a assistência à saúde, em qualquer contexto.

Todavia, imperioso compreender que o princípio da integralidade que norteia o sistema público de saúde não pode ser confundido com o atendimento médico e diagnóstico terapêutico desmedido, sob pena de desnaturar o real conteúdo da norma positivada.

Com efeito, talvez seja conveniente deixar claro que a denominada universalidade deve corresponder à compreensão de que a integralidade acima transcrita na Constituição Federal autoriza, por si só, a todo e qualquer cidadão fazer uso da máquina estatal, utilizando o serviço público de saúde.

Data vênia, entendemos que o sentido da integralidade previsto na norma constitucional, tem como destinatário a pessoa e não o serviço, interpretação que parece ainda mais consentânea com os supracitados princípios do acesso universal e do acesso igualitário.

Nesse passo, o direito público subjetivo açambarcado pelo mencionado artigo 196, é o de que todos tenham condições iguais de acesso à saúde pelo Estado, ou, em outras palavras:

22 ARAÚJO, Luiz Alberto David; NUNES JR., Vidal Serrano. Curso de direito constitucional. 12. ed. rev. e atual. São Paulo: Saraiva, 2008. p. 486p. 395. 
serviços postos à disposição a todos, mas somente aqueles factíveis de serem executados, jamais a universalidade deles, cuja ideia, repita-se à exaustão, é augusta, mas evidentemente inexequível por qualquer ângulo que se queira enxergar.

A universalidade e a igualdade, pois, se dirigem à pessoa e não ao objeto do serviço a ser prestado.

Não se pode dissociar a previsão constitucional das demais normas pertinentes ao tema, em especial à realidade orçamentária: o Estado não é despensa de medicamento, nem provedor universal de procedimentos na área da saúde. Harmonizar os fenômenos sócioeconômicos e a ordem jurídica é medida de rigor para fixar limites responsáveis de atuação do poder público e propiciar o atendimento de maneira equânime e isonômica à sociedade.

Calha ressaltar que tem sido esta a ideia prevalecente, inclusive em âmbito internacional, já que até mesmo o Comitê de Direitos Econômicos, Sociais e Culturais (CDESC), da Organização das Nações Unidas (ONU), ao emitir observações gerais relativas ao cumprimento às disposições do Pacto Internacional de Direitos Econômicos, Sociais e Culturais (PIDESC) - do qual o Brasil é signatário -, de caráter vinculativo, frise-se, distingue com maestria obrigações mínimas e obrigações esperadas, na área da saúde:

"Quando o CDESC aponta as obrigações de respeitar, de proteger e de promover, há que tomar um cuidado especial. Uma parte dessas obrigações são concretizações das obrigações mínimas e outra das obrigações esperadas. A não distinção desses subconjuntos pode levar a uma interpretação errada das obrigações inescusáveis e escusáveis. O conjunto das obrigações inescusáveis abarca as obrigações básicas, as obrigações mínimas de respeitar e as obrigações mínimas de proteger". ${ }^{23}$

Portanto, é fundamental à compreensão do alcance da universalidade do Direito à Saúde, que por ela o Estado tem o dever de garantir o seu acesso a todos, mas não a tudo, sob pena de se incorrer em distorções das quais se falará mais amiúde adiante.

\section{A APLICABILIDADE DA TEORIA DA RESERVA DO POSSÍVEL E DO MÍNIMO EXISTENCIAL: REPÚDIO À "ESCOLHA TRÁGICA”}

A reserva do possível - tese surgida na Corte Constitucional Alemã, em um caso no qual se discutiu o direito de acesso a vagas em universidades naquele país -, é uma condição de realidade que determina a submissão dos direitos fundamentais prestacionais aos recursos

${ }^{23}$ LAMY, Marcelo et al. Violação das Obrigações Estatais na Área da Saúde: A Diferença entre as obrigações mínimas e as esperadas. Caderno de Relações Internacionais, vol. 7, n 13, ago-dez, 2016, p. 297-316. 
existentes; um argumento legítimo, a priori, para que se exima o Estado de prover determinado direito até que cesse a causa da impossibilidade.

Segundo a doutrina: "A expressão "reserva do possível" é utilizada largamente na doutrina para identificar o fenômeno da limitação de recursos frente à necessidade de aplicação dos mesmos para concreção dos direitos sociais"24.

Destaca-se não como uma questão financeira de escassez de recursos, mas como uma questão de razoabilidade na alocação de recursos; com efeito, adotadas as necessárias cautelas, não há como se negar a validade do instituto para o equacionamento de questões relativas à exigibilidade dos direitos sociais.

Até mesmo porque a escassez de recursos não restringe ou derroga o direito à saúde, sendo tão somente um entrave na prestação de um dever constitucional.

Noutras palavras, pensamos que adotadas as necessárias cautelas, não há como se negar a validade do instituto para o equacionamento de questões relativas à exigibilidade dos direitos sociais, ainda que dentre eles cá se esteja tratando do mais importante, que é o da saúde.

Para Ingo Wolfgang Sarlet ${ }^{25}$, a reserva do possível apresenta três dimensões, quais sejam:

“a) a efetiva disponibilidade fática dos recursos para a efetivação dos direitos fundamentais;

b) a disponibilidade jurídica dos recursos materiais e humanos, que guarda íntima conexão com a distribuição das receitas e competências tributárias, orçamentárias, legislativas e administrativas, entre outras, e que, além disso, reclama equacionamento, notadamente no caso do Brasil, no contexto do nosso sistema constitucional federativo;

c) já na perspectiva (também) do eventual titular de um direito a prestações sociais, a reserva do possível envolve o problema da proporcionalidade da prestação, em especial no tocante à sua exigibilidade e, nesta quadra, também da sua razoabilidade.

Para a operacionalização do instituto, mister se faz analisar se, no caso concreto, a distribuição dos recursos orçamentários está ou não em conformidade aos mínimos constitucionais e as prioridades estabelecidas na Constituição, pois uma vez configurada a insuficiência artificial de recursos, eventual oposição do argumento da reserva do possível mostrar-se-á de maneira mitigada."

\footnotetext{
24 BARCELLOS, Ana Paula de. Educação, constituição, democracia e recursos públicos. Revista de Direito da Associação dos Procuradores do Novo Estado do Rio de Janeiro, vol. 12, Lumen Juris, Rio de Janeiro, 2003, p. 47 (apud PESSANHA, Érica. A eficácia dos direitos sociais prestacionais. Revista da Faculdade de Direito de Campos, ano VII, n. 8, jun. 2006).

25 SARLET, Ingo Wolfgang e FIGUEIREDO, Mariana Filchtiner. Reserva do possível, mínimo existencial e direito à saúde: algumas aproximações. In: SARLET, I. W. e TIMM, L.B. Direitos Fundamentais: orçamento e "reserva do possível". Porto Alegre: Livraria do Advogado, 2010.
} 
Depreende-se que não basta o Estado alegar a reserva do possível para justificar o não cumprimento de um dever constitucional; em verdade, precisa ir além, demonstrando, de maneira cabal, a impossibilidade de atender a demanda, sob pena de - saliente-se à exaustão arrostar o princípio do acesso igualitário ao direito à saúde.

Assim, impende observar duas premissas básicas para a invocação da reserva possível pelo Estado: a previsão equilibrada de verbas públicas para o segmento da saúde e a ocorrência de uma impossibilidade invencível.

Destarte, o poder público carrega o ônus de demonstrar que alocou os recursos orçamentários necessários para a promoção dos direitos sociais voltados para a área da saúde. Igualmente, deverá o Estado provar que a inviabilidade de concretizar o direito reclamado decorre de uma barreira intransponível - ainda que momentaneamente - e não de uma omissão.

Não basta, portanto, a reserva financeiramente possível, mas também a razoabilidade da pretensão buscada para que se possa exigir do Estado a prestação almejada.

Ademais, é fundamental que tal direito possa estar ao alcance de todos em idêntica situação de necessidade, já que o princípio igualitário do acesso à saúde de que falamos acima estaria irremediavelmente fulminado se, por exemplo, o Estado - por meio do Poder Executivo ou do Judiciário, pouco importa -, conceder a um que dele se socorre, medicamento que custa alguns milhares de dólares, em detrimento de outro, que se conforma com a negativa a esse pleito, por não dispor dos mesmos meios e recursos de que se valeu o outro.

Nessa toada, Robert Alexy26 leciona que:

\begin{abstract}
"Em uma constituição como a brasileira, que conhece direitos fundamentais numerosos, sociais generosamente formulados, nasce sobre esse fundamento uma forte pressão de declarar todas as normas não plenamente cumpríveis, simplesmente, como não vinculativas, portanto, como meras proposições programáticas. A teoria dos princípios pode, pelo contrário, levar a sério a constituição sem exigir o impossível. Ela declara as normas não plenamente cumpríveis como princípios que, contra outros princípios, devem ser ponderados e, assim, estão sob uma 'reserva do possível' no sentido daquilo que o indivíduo pode requerer de modo razoável da sociedade.”
\end{abstract}

26 ALEXY, Robert. Constitucionalismo discursivo. Tradução de Luís Afonso Heck. $3^{\mathrm{a}}$ ed.rev. Porto Alegre: Livraria do Advogado Editora, 2011, p. 69. 
Com efeito, o direito não aceita a exigência de prestações impossíveis, mas roga pela proporcionalidade do que se pretende, ou seja, a teoria da reserva do possível consiste naquilo que é efetivamente viável realizar, ante as circunstâncias fáticas e jurídicas do caso concreto.

Consoante conclui Virgílio Afonso da Silva"27, "se toda não-realização de direitos que exigem uma intervenção estatal é uma forma de restrição ao âmbito de proteção desses direitos, a consequência natural, como ocorre em todos os casos de restrições a direitos fundamentais, é uma exigência de fundamentação. Restrição fundamentada é restrição possível; restrição não-fundamentada é violação."

Não se desconhece que o Supremo Tribunal Federal rechaça a teoria da reserva do possível quando a quaestio iuris envolve direitos sociais:

(...) A CONTROVÉRSIA PERTINENTE À "RESERVA DO POSSÍVEL” E A
INTANGIBILIDADE DO MÍNIMO EXISTENCIAL: A QUESTÃO DAS “ESCOLHAS
TRÁGICAS". - A destinação de recursos públicos, sempre tão dramaticamente
escassos, faz instaurar situações de conflito, quer com a execução de políticas
públicas definidas no texto constitucional, quer, também, com a própria
implementação de direitos sociais assegurados pela Constituição da República, daí
resultando contextos de antagonismo que impõem, ao Estado, o encargo de superá-
los mediante opções por determinados valores, em detrimento de outros igualmente
relevantes, compelindo, o Poder Público, em face dessa relação dilemática, causada
pela insuficiência de disponibilidade financeira e orçamentária, a proceder a
verdadeiras "escolhas trágicas", em decisão governamental cujo parâmetro,
fundado na dignidade da pessoa humana, deverá ter em perspectiva a
intangibilidade do mínimo existencial, em ordem a conferir real efetividade às
normas programáticas positivadas na própria Lei Fundamental. Magistério da
doutrina. - A cláusula da reserva do possivel - que não pode ser invocada pelo
Poder Público com o propósito de fraudar, de frustrar e de inviabilizar a
implementação de politicas públicas definidas na própria Constituição, encontra
insuperável limitação na garantia constitucional do minimo existencial, que
representa, no contexto de nosso ordenamento positivo, emanação direta do
postulado da essencial dignidade da pessoa humana." 28

Todavia, ainda que o núcleo da teoria em pauta traga embaraço à efetivação dos direitos fundamentais, não se pode negar que, em determinadas situações deduzidas em juízo, os princípios constitucionais orçamentários não constituem obstáculos para a acolhida da tese da reserva do possível.

27 SILVA, Virgílio Afonso da. Direitos Fundamentais - conteúdo essencial, restrições e eficácia. $2^{\text {a }}$ ed. São Paulo: Malheiros Editores, 2010.

28 Decisão proferida no ARE 639337 AgR/SP. AG.REG. NO RECURSO EXTRAORDINÁRIO COMAGRAVO. Relator: Min. CELSO DE MELLO. Julgamento: 23/08/2011, AGTE.: MUNICÍPIO DE SÃOPAULO, AGDO.: MINISTÉRIO PÚBLICO DO ESTADO DE SÃO PAULO. 
À guisa de exemplo, curiosamente, a mesma Egrégia Corte Superior acolhe a teoria em comento para justificar o não pagamento de precatórios ${ }^{29}$, relacionando a cláusula à disponibilidade financeira, mencionando "a reserva do financeiramente possivel".

Acerca do tema, Daniel Wei Liang Wang ${ }^{30}$ observa que "as decisões dos ministros do Supremo Tribunal Federal em matéria de intervenção federal pelo não pagamento de precatórios tratam, em sua maior parte, da escassez de recursos, dos custos dos direitos e da reserva do possivel de forma muito diferente daquelas que versam sobre o direito à saúde e à educação".

Sublinha-se, ainda, que "a reserva do financeiramente possível" também foi reconhecida em sede de repercussão geral pelo STF em questão envolvimento o excesso de população carcerário e o pedido de dano moral. Confira-se a ementa do julgado:

\begin{abstract}
Limites orçamentários do Estado. Indenização por dano moral. Excessiva população carcerária. Presença da repercussão geral. Possui repercussão geral a questão constitucional atinente à contraposição entre a chamada cláusula da reserva financeira do possível e a pretensão de obter indenização por dano moral decorrente da excessiva população carcerária. (STF - RE 580252 RG, Relator(a): Min. Ayres Britto, julgado em 17/02/2011, DJE-109 divulg 07-06-2011 public 08-06-2011 ement vol-02539-02 pp-00325 )
\end{abstract}

Todavia, a discussão não parece serenada, em especial perante o Colendo Tribunal de Justiça do Estado de São Paulo, que em alguns julgados tem recorrido a essa teoria como meio de sintonizar a necessidade do jurisdicionado, com o que seria razoável se esperar da capacidade econômico-financeira do Estado:

AÇÃO ORDINÁRIA - Autora portadora de infertilidade que almeja o fornecimento
de medicamentos de alto curso (Synarel, Puregon ou Gonal, e Ovidrel) "por prazo
indeterminado", com vistas à realização de reprodução assistida Descabimento no
caso, uma vez que não demonstrado o risco iminente de morte, possibilitando, com
base na reserva do possível, a limitação do fornecimento dos medicamentos em 3
(três) tentativas Precedentes deste E. Tribunal de Justiça - Procedência parcial da
ação decretada Recurso da Fazenda do Estado provido em parte. (TSSP - AC $n^{o}$
$0101758-89.2010 .8 .26 .0222$ - Rel. Des. Rebouças de Carvalho, j. $11.02 .16, v . u$.)

Ação civil pública. Serviço Social dos Municipiários de Ribeirão Preto. Pretensão à obrigatoriedade de oferta de teste NAT para detecção de infecção de hepatite e HIV. Necessidade da verificação da oportunidade da medida. Serviço não integrante do SUS, custeado pelo contribuinte, e distinto do privado suplementar. Reserva do possivel que se aplica. Inexistência de prova de disponibilidade orçamentária. Ação ora julgada improcedente. Recurso voluntário e reexame necessário providos.

29 Vide: IF 470/SP. INTERVENÇÃO FEDERAL. Relator: Min. MARCO AURÉLIO. Relator p/ Acórdão: Min. GILMAR MENDES. Julgamento: 26/02/2003. REQTE.:VALDIR FRANCISCO SIMOES E OUTROS. REQDO.: ESTADO DE SÃO PAULO.

30 WANG, Daniel Wei Liang. Escassez de recursos, custos dos direitos e reserva do possível na jurisprudência do STF. Disponível em $<\underline{\text { http://www.scielo.br/pdf/rdgv/v4n2/a09v4n2.pdf }>}$ 
(TJSP - AC n $n^{\circ}$ 0241235-51.2009.8.26.0000 - Rel. Des. Luis Fernando Camargo de Barros Vidal, j. 16.09.13, v.u.)

De fato, ainda que o atendimento à saúde dos cidadãos não possa ser relegado a segundo plano, sem admitir quaisquer subterfúgios interpretativos no sentido de que tais deveres constitucionais sejam encapsulados num conceito quase que indeterminado de normas programáticas - de cuja aplicabilidade progressiva dependa de disponibilidade financeira do ente Público -, é de se convir que, de outro tanto, este campo de abstração há de ceder à efetiva concretude do texto constitucional.

Porém, mesmo que se acolhesse a premissa de que a saúde é direito priorizado pelo Estado, ainda assim não será possível ao ente público absorver todos os desejos e demandas nessa área, mesmo que justos e justificáveis.

Em que pesem as discussões doutrinárias e controvérsias jurisprudências ainda pulsantes acerca do tema, é impostergável concluir que a reserva do possível não se resume somente à disponibilidade financeira, mas abarca também a razoabilidade da pretensão, ainda que o direito em disputa seja o da saúde.

\section{CONCLUSÃO}

A Constituição Federal de 1988, em seu artigo $6^{\circ}$, instituiu a saúde como um Direito Social, e como Direito Fundamental traz em seu cerne uma política que garante o acesso universal e igualitário a todos que dela necessitem. Eis a ideia que temos do preceito constitucional: não se deve excluir ninguém do acesso igualitário à prestação de serviços na área da saúde postos à disposição pelo Estado, por meio do SUS.

Assim, sendo a saúde uma espécie do gênero seguridade social, são duas as vertentes que sobre ela recaem no espectro estatal: a preventiva e a curativa.

Sob o viés preventivo, o Direito à Saúde abrange o dever estatal de formular e implementar políticas públicas com o escopo de evitar doenças, proliferação de endemias, exigindo-se, enfim, uma atuação positiva do estado. Noutro enfoque, o caráter curativo do direito à saúde consiste na oferta de assistência médica, medicamentosa, ambulatorial e hospitalar. 
O grande desafio do gestor público na implementação das políticas públicas voltadas aos Direitos Sociais denominados prestacionais, como a saúde, está, precisamente, na busca pelo equilíbrio e pela equanimidade do emprego dos recursos públicos, pois se nos afigura mais justo, do ponto de vista isonômico, que todos tenham o mesmo quinhão de fruição deles.

Evita-se, pois, que se garanta muito a poucos, e pouco a muitos, sobretudo porque, como já se afirmou, a universalidade e a igualdade esculpidas no artigo 196, da Constituição Federal, são premissas que se dirigem à pessoa e não ao objeto a ser a ela prestado.

Ocorre que na ânsia de obter a concretude do ideal imaginário, alguns recorrem ao Poder Judiciário para a realização das suas pretensões, muitas delas sem o menor cuidado ou preocupação com o orçamento público, a nosso ver fazendo emergir a pertinência da teoria da reserva do possível, evitando que o Estado seja compelido a realizar escolhas trágicas.

Nasce, então, o desejo à obtenção da saúde a qualquer preço, e o direito individual atinge o seu ápice em detrimento do direito social do qual é espécie, desvirtuando o conceito de universalidade das políticas de saúde e desaguando em desigualdade dicotômica, pois, de um lado, os protegidos pelo manto excessivo do Poder Judiciário têm satisfeitos seus anseios, enquanto, de outro, os demais são financiados pela sobra orçamentária, permanecendo dependentes de uma universalidade meramente teórica e retórica, ao tornar flagrantemente desiguais aqueles em idêntica condição de necessidade.

O Poder Judiciário, assim, tem ocupado temerário protagonismo nessa equação pública, ao se mostrar em quase completa alienação à visão da indispensável contrapartida orçamentária, involuntariamente alimentando o caos instalado na Saúde Pública, em que não raro o Estado se vê forçado a custear tratamentos extraordinariamente dispendiosos e individualizados, por submissão à ordem judicial, desfalcando verbas que se destinariam, muita vez, a sustentar a mais elementar medicina preventiva e curativa à toda coletividade.

Essa perigosa intervenção judicial na administração pública tem propiciado, por conseguinte, não só a inviabilização da universalização do acesso à saúde de que se cogitou no referido artigo 196 - inclusive quanto às obrigações mínimas -, como também potencializado a judicialização desse direito, tanto na seara pública, quanto na privada.

Nessa vereda, o que se assiste, atualmente, é a almejada universalidade ameaçada, em que o acesso igualitário teorizado constitucionalmente é convertido em uma realidade 
desajustada - quer pela má organização administrativa, quer pela intervenção judicial -, a desafiar o operador de Direito e o gestor público.

O que aqui se propõe, portanto, é um novo olhar para o que se entende por universalidade do direito à saúde: ela consistiria, em verdade, na busca por se atingir o inteiro espaço ocupado pelos que dela necessitam e utilizam, ao menos quanto às obrigações mínimas e inescusáveis do Estado, tanto na esfera preventiva, quanto na curativa.

A teoria na qual se assenta a reserva do possível, no nosso entender, não destoa da ideia da universalidade do Direito à Saúde; ao reverso, vai ao encontro, sobretudo, do princípio igualitário de que já se falou alhures, permitindo que os recursos orçamentários disponíveis estejam à disposição não de um ou outro que reclame determinada prestação nessa área, mas sim de todos os que estiverem em idêntica situação.

O arremate a que se pode chegar, portanto, toma a direção segundo a qual a universalidade deve ser entendida quanto aos seus destinatários e deve ser distribuída entre eles equanimemente, dentro da reserva do possível, do mínimo existencial e do planejamento contido no orçamento público, não se podendo ignorar que, se inserida em relação jurídica de direito privado, não se poderá cogitar da universalidade que é, unicamente, dever do Estado.

\section{REFERÊNCIAS BIBLIOGRÁFICAS}

AGUIAR, Flávio. Eficiente e Deficiente: o sistema de Saúde na Alemanha. Disponível em: $<$ http://www.cartamaior.com.br/?/Coluna/Eficiente-e-deficiente-o-sistema-de-saude-naAlemanha/20685> Acesso em: 10/07/2017.

ALEXY, Robert. Constitucionalismo discursivo. Tradução de Luís Afonso Heck. 3. ed.rev. Porto Alegre: Livraria do Advogado Editora, 2011.

ARAÚJO, Luiz Alberto David; NUNES JR., Vidal Serrano. Curso de direito constitucional. 12. ed. rev. e atual. São Paulo: Saraiva, 2008.

BARCELLOS, Ana Paula de. Educação, constituição, democracia e recursos públicos. Revista de Direito da Associação dos Procuradores do Novo Estado do Rio de Janeiro, vol. 12, Rio de Janeiro: Lumen Juris, 2003 (apud PESSANHA, Érica. A eficácia dos direitos sociais prestacionais. Revista da Faculdade de Direito de Campos, ano VII, n. 8, jun. 2006).

BARROSO, Luiz Roberto. Da falta de efetividade à judicialização excessiva: direito à saúde, fornecimento gratuito de medicamentos e parâmetros para a atuação judicial. Disponível em: <www.lrbarroso.com.br/pt/noticias/medicamentos.pdf.> Acesso em: 12.09.2009. p. 8 . 
LAMY, Marcelo et al. Violação das Obrigações Estatais na Área da Saúde: A Diferença entre as obrigações mínimas e as esperadas. Caderno de Relações Internacionais, vol. 7, $\mathrm{n}^{\circ}$ 13 , ago-dez/16.

MARTINS, Ives Gandra da Silva; SOUZA, Fátima Fernandes Rodrigues de. Serviços de saúde. Relevância pública independente do regime de sua prestação. Participação da iniciativa privada em caráter complementar ao SUS. Direito à manutenção do equilíbrio econômico e financeiro dos contratos e/ou convênios celebrados com a administração. Reajuste e recomposição de preços. Exigência constitucional e da legislação ordinária para que os valores repassados reflitam os impactos da inflação e do aperfeiçoamento tecnológico dos procedimentos. Parecer. Revista IOB de Direito Administrativo, vol. 2, n. 14, São Paulo, IOB Thomson.

MEIRELLES, Hely Lopes. Direito Municipal Brasileiro. 14. Ed. São Paulo: Malheiros, 2006.

MENDES, Áquilas. A busca da cumplicidade entre o planejamento e o processo orçamentário na saúde paulistana. In: MENDES Áquilas; SOUZA, Maria de Fátima de (Orgs). Tempos radicais da saúde em São Paulo: a construção do SUS na maior cidade brasileira. São Paulo: Hucitec.

ORDACGY, André da Silva. O direito humano fundamental à saúde pública. Disponível e m : < w w w. h e m o f i 1 i a b r a s i 1 . o r g. b r / a r t i g o s / artigo_20080925170800ARTIGO_SAUDE_PUBLICA_ANDRE_ORDACGY_ESDPU.pdf.> Acesso em: 31.08.2009.

SANTOS, Lenir. SUS: contornos jurídicos da integralidade da atenção à saúde. In: Luiz Odorico Monteiro de Andrade, SUS passo a passo. São Paulo: Hucitec, 2008.

Direito à Saúde, Sistema Único de Saúde e a Integralidade da Assistência. In: Direito da Saúde no Brasil. André Evangelista de Souza et al. Organizadora: Lenir Santos. São Paulo, Saberes Editora, 2010

SARLET, Ingo Wolfgang e FIGUEIREDO, Mariana Filchtiner. Reserva do possível, mínimo existencial e direito à saúde: algumas aproximações. In: SARLET, I. W. e TIMM, L.B. Direitos Fundamentais: orçamento e "reserva do possível". Porto Alegre: Livraria do Advogado, 2010.

SILVA, Virgílio Afonso da. Direitos Fundamentais - conteúdo essencial, restrições e eficácia. 2. ed. São Paulo: Malheiros Editores, 2010.

WANG, Daniel Wei Liang. Escassez de recursos, custos dos direitos e reserva do possível

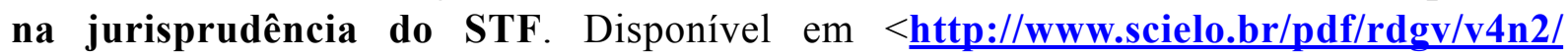
a09v4n2.pdf $>$. Acesso em 10/06/2017.

WEICHERT, Marlon Alberto. Direito à saúde, Sistema Único de Saúde e a integralidade da assistência. In: Direito da Saúde no Brasil. André Evangelista de Souza et al. Organizadora: Lenir Santos. São Paulo, Saberes Editora, 2010. 